\title{
Spatial and temporal patterns of drought in Zambia
}

\author{
Brigadier LIBANDA ${ }^{1 *},{\text { ZHENG } \mathrm{Mie}^{2} \text {, Chilekana NGONGA }}^{3}$ \\ ${ }^{1}$ School of Geosciences, The University of Edinburgh, EH9 3FF, Edinburgh, United Kingdom; \\ ${ }^{2}$ School of Civil Engineering and Geosciences, Newcastle University, NE1 4LY, Newcastle, United Kingdom; \\ ${ }^{3}$ Ministry of Energy and Water Development, Lusaka, PO Box 53930, Zambia
}

\begin{abstract}
Drought acutely affects economic sectors, natural habitats and communities. Understanding the past spatial and temporal patterns of drought is crucial because it facilitates the forecasting of future drought occurrences and informs decision-making processes for possible adaptive measures. This is especially important in view of a changing climate. This study employed the World Meteorological Organization (WMO)-recommended standardized precipitation index (SPI) to investigate the spatial and temporal patterns of drought in Zambia from 1960 to 2016. The relationship between the occurrence of consecutive dry days (CDD; consecutive days with less than $1 \mathrm{~mm}$ of precipitation) and SPI was also investigated. Horizontal wind vectors at $850 \mathrm{hPa}$ during the core of the rainy season (December-February) were examined to ascertain the patterns of flow during years of extreme and severe drought; and these were contrasted with the patterns of flow in 2007, which was a generally wet year. Pressure vertical velocity was also investigated. Based on the gamma distribution, SPI successfully categorized extremely dry (with a SPI value less than or equal to -2.0) years over Zambia as 1992 and 2015, a severely dry (-1.9 to -1.5$)$ year as 1995 , moderately dry $(-1.4$ to -1.0$)$ years as $1972,1980,1987,1999$ and 2005 , and 26 near normal years $(-0.9$ to 0.9$)$. The occurrence of CDD was found to be strongly negatively correlated with SPI with a coefficient of -0.6. Further results suggest that, during wet years, Zambia is influenced by a clockwise circulating low-pressure zone over the south-eastern Angola, a second such zone over the northern and eastern parts, and a third over the Indian Ocean. In stark contrast, years of drought were characterized by an anti-clockwise circulating high-pressure zone over the south-western parts of Zambia, constraining precipitation activities over the country. Further, wet years were characterized by negative pressure vertical velocity anomalies, signifying ascending motion; while drought years were dominated by positive anomalies, signifying descending motion, which suppresses precipitation. These patterns can be used to forecast drought over Zambia and aid in strategic planning to limit the potential damage of drought.
\end{abstract}

Keywords: standardized precipitation index; patterns of drought; consecutive dry days; vertical velocity; gamma distribution; rainfall

Citation: Brigadier LIBANDA, ZHENG Mie, Chilekana NGONGA. 2019. Spatial and temporal patterns of drought in Zambia. Journal of Arid Land, 11(2):180-191. https://doi.org/10.1007/s40333-019-0053-2

\section{Introduction}

The World Meteorological Organization (WMO) defines a meteorological drought as an extended period of dryness in the natural climate cycle compared to the 30-year average of the region under study (Monacelli, 2005). Exploring patterns of drought is of interest because of its detrimental effects on socio-economic activities. These impacts have been well documented for different parts

\footnotetext{
*Corresponding author: Brigadier LIBANDA (E-mail: brigadier.libanda@ed.ac.uk)

Received 2017-12-15; revised 2018-04-25; accepted 2018-05-17

(C) Xinjiang Institute of Ecology and Geography, Chinese Academy of Sciences, Science Press and Springer-Verlag GmbH Germany, part of Springer Nature 2019
} 
of the world in recent years (Santos et al., 2010; Udmale et al., 2014). Over Africa, a recent study conducted by Uhe et al. (2017) showed that Kenya suffered severe drought following low precipitation coupled with high temperature towards the end of 2016.

In the face of a changing climate (Field et al., 2012), the intensity and frequency of drought are projected to increase with an increase in radiative forcing, especially by the end of the $21^{\text {st }}$ century (Taylor et al., 2012; Zhao and Dai, 2015). These changes will lead to damaging impacts on natural ecosystems, cause dire shortages of basic needs such as water and food and lead to an increase in heat waves, resulting in wild fires (Dai, 2011). Statistical links between climate change and occurrences of drought have been documented (Burke, 2011). Although it has been noted that below normal precipitation is the main driver of drought (Trenberth and Fasullo, 2009; Zhao and Dai, 2015), a warming climate increases evapotranspiration, which may lead to more pronounced droughts (Scheff and Frierson, 2012). Southern Africa is particularly vulnerable to climate-change-induced drought because of its dependence on climate-driven sectors such as rain-fed agriculture, and services provided by ecosystems (Loomis, 1999).

As part of southern Africa, Zambia has been experiencing the impacts of drought for some time now. For example, Hill (2016) attributed the drying up of Lake Kariba to drought. Lake Kariba, the world's largest man-made lake by volume, contributes significantly to hydroelectricity, fisheries, and agricultural activities (Muchuru et al., 2014). It's drying up has therefore been a source of concern to policy makers and has attracted regional and international attention (Hill, 2016; New Yorker, 2016). Invariably, during years that Zambia has experienced drought, Lake Kariba has experienced dangerously low water levels, leading to a reduction in power generation and consequently adversely affecting socio-economic activities in both Zambia and Zimbabwe (Hill, 2016). Although there is some documentation on the impacts of drought in Zambia, patterns of drought occurrences, and circulation mechanisms driving the drought remain poorly understood.

Given the negative effects of drought, it follows that the primary protection against this phenomenon is a proper understanding of its past patterns in order to understand its probable future occurrence(s). In examining past drought patterns, diverse methodological approaches have been used around the world. Some studies (e.g., Okoola, 1999; Ogwang et al., 2012) have utilized composite analysis to examine atmospheric mechanisms affecting precipitation during drought years.

In this study, the standardized precipitation index (SPI) was used to explore the patterns of drought because of its convenience in categorizing them (McKee et al., 1993; Hayes et al., 2011; Ngarukiyimana et al., 2017). SPI is based on precipitation data only, and it runs a comparative analysis of annual average precipitation and transforms the data to a normal distribution in order to avoid errors. The transformation to a normal distribution is performed using an equal-probability transformation after fitting the precipitation data to a gamma distribution (Zargar et al., 2011). The average is then fitted to zero with above-zero values denoting relatively high precipitation and below-zero values denoting drought.

The main goal of this study is to investigate spatial and temporal patterns of drought in Zambia over a 56-year period (1960-2016). As in Zargar et al. (2011), drought was used in this study to represent a stochastic natural hazard, which is triggered by rainfall failure associated with persistent synoptic mechanisms, affecting water resources, agriculture, and socio-economic activities. As well as precipitation itself, circulation mechanisms related to extremely and severely dry years are also investigated in this study. The findings highlight mechanisms that must carefully be monitored in the future for strategic planning to avert losses associated with drought.

\section{Materials and methods}

\subsection{Study area}

Zambia is located in the southern parts of Africa (longitudes $21^{\circ} 30^{\prime} \mathrm{E}$ to $34^{\circ} 00^{\prime} \mathrm{E}$ and latitudes $18^{\circ} 00^{\prime} \mathrm{S}$ to $\left.08^{\circ} 00^{\prime} \mathrm{S}\right)$. Generally, much of the landmass in Zambia lies between 910 and $1200 \mathrm{~m}$ above sea level (a.s.l.). Zambia can therefore be classified as a plateau with peak points (more 
than $1800 \mathrm{~m}$ a.s.1.) being found along the Muchinga Escarpment (northeast) and the Mafinga hills (east) and lower points (less than $610 \mathrm{~m}$ a.s.l.) in the valleys of the Luangwa and Zambezi rivers.

Zambia experiences a bimodal precipitation pattern with a distinct dry season from April to September and a wet season from late October to early April next year. Many studies (e.g., Tiffen and Mulele, 1994; Hachigonta and Reason, 2006; Libanda et al., 2015) have found statistical links between the onset/cessation of rainfall and the movements of the Inter Tropical Convergence Zone (ITCZ). The ITCZ is a low-pressure system that occurs when the north-eastern trade winds, moist air from the Congo basin, and the meridional south-eastern trade winds converge (Libanda et al., 2017a). This low-pressure zone triggers precipitation events. The ITCZ begins to affect Zambia from the north and north-west around October or November, causing the northern half of the country to experience increased precipitation while most parts of the southern half remain relatively dry. From December to February, the ITCZ travels southwards bringing precipitation to the southern half of the country before withdrawing to give a second precipitation peak in the northern half in March or April (Libanda et al., 2017b). Total annual average precipitation in the northern half of the country is $1400 \mathrm{~mm}$ while the southern half receives about $600 \mathrm{~mm}$ (Libanda et al., 2015).

\subsection{Data sources}

The datasets used in this study are summarized in Table 1. Specifically, Global Precipitation Climatology Centre (GPCC) precipitation data were used to calculate the occurrences of drought. This dataset is monthly, and it is gridded with a spatial resolution of $0.5^{\circ} \times 0.5^{\circ}, 1.0^{\circ} \times 1.0^{\circ}$, and $2.5^{\circ} \times 2.5^{\circ}$ latitude by longitude. It is described in detail by Schneider et al. (2016) and is available through the Physical Science Division of the Earth System Research Laboratory (https://www.esrl.noaa.gov/psd/data/gridded).

Table 1 Summary of datasets the used in this study

\begin{tabular}{|c|c|c|c|}
\hline Dataset & Source & Resolution & Period used \\
\hline GPCC & $\begin{array}{l}\text { Physical Science Division, Earth System } \\
\text { Research Laboratory }\end{array}$ & $0.5^{\circ} \times 0.5^{\circ}$ & 1960-2016 \\
\hline $\mathrm{ARC} 2$ & Climate Prediction Center & $0.1^{\circ} \times 0.1^{\circ}$ & $1983-2016$ \\
\hline $\begin{array}{l}\text { Relative humidity, zonal } \\
\text { and meridional winds }\end{array}$ & $\begin{array}{l}\text { European Centre for Medium-Range Weather } \\
\text { Forecasts }\end{array}$ & $0.75^{\circ} \times 0.75^{\circ}$ & $\begin{array}{c}2007 \text { (wet); } 1995 \text { (severely } \\
\text { dry); } 1992 \text { and } 2015 \text { (extremely } \\
\text { dry) }\end{array}$ \\
\hline $\begin{array}{l}\text { Pressure vertical velocity } \\
\text { (omega) }\end{array}$ & $\begin{array}{c}\text { National Centers for Environmental } \\
\text { Prediction/National Center for Atmospheric } \\
\text { Research }\end{array}$ & $2.5^{\circ} \times 2.5^{\circ}$ & $\begin{array}{c}2007 \text { (wet); } 1995 \text { (severely } \\
\text { dry); } 1992 \text { and } 2015 \text { (extremely } \\
\text { dry) }\end{array}$ \\
\hline Topographical data & $\begin{array}{l}\text { Joint Institute for the Study of the Atmosphere } \\
\text { and Ocean }\end{array}$ & $1^{\circ} \times 1^{\circ}$ & \\
\hline
\end{tabular}

In this study, the maximum number of consecutive days with less than $1 \mathrm{~mm}$ of precipitation was investigated because it serves as a reliable measure of the evolution of seasonal drought (Duan et al., 2016). Originally, the theory of consecutive dry days (CDD) was proposed by Frich et al. (2002) in their study on variations and changes in extreme climate towards the end of the $20^{\text {th }}$ century. Subsequently, during the CLIVAR/GCOS/WMO workshop on indices and indicators for climate extremes, the Expert Team on Climate Change Detection and Indices (ETCCDI) adopted this index and included it in the 27 core climate change indices, which have since been employed by many studies quantifying climate change worldwide (Karl et al., 1999; Ongoma et al., 2017; Libanda and Ngonga, 2018).

To investigate the evolution of CDD, we obtained daily rainfall data (Africa Rainfall Climatology Version 2; ARC2) from the archives of the Climate Prediction Center and the data are freely available at https://iridl.ldeo.columbia.edu. This dataset is a blend of rain gauge and satellite information. It is of high quality and is gridded at a spatial resolution of $0.1^{\circ} \times 0.1^{\circ}$ (Novella and Thiaw, 2013). The period covered for the calculation of CDD in this study is 1983 to 2016. We chose this period based on data availability. Unlike GPCC monthly data that covers a longer period of time, ARC2 daily rainfall is only available for the period 1983-present. 
Relative humidity (RH), and zonal and meridional winds were studied, on the basis of ERA-interim reanalysis data (https://www.ecmwf.int; Dee et al., 2011). These datasets are gridded at a resolution of $0.75^{\circ} \times 0.75^{\circ}$. They are of high quality, and many studies (e.g., Nicholson and Grist, 2003; Bordi et al., 2005; Libanda et al., 2016) have used them in different parts of the world.

The topographical dataset used in this study is a product of the Joint Institute for the Study of the Atmosphere and Ocean (JISAO; http://jisao.washington.edu). It is a $1^{\circ} \times 1^{\circ}$ latitude-longitude resolution elevation dataset.

\subsection{Data analysis}

Using a gamma distribution probability density function, SPI was computed as:

$$
g(x)=\frac{1}{\beta^{\alpha \Gamma(\alpha)}} x^{\alpha-1_{\mathrm{e}}^{\frac{-x}{\beta}}}(x>0),
$$

where $\Gamma(\alpha)$ represents the gamma function; $x$ is the amount of precipitation in $\mathrm{mm}(x>0)$; $\alpha$ is the shape parameter; and $\beta$ is the scale parameter $(\beta>0)$. Many studies (e.g., Dogan et al., 2012; Salehnia et al., 2017) have used this method for drought characterization in different parts of the world.

The classification of drought years in this study was performed following McKee et al. (1993) and it is given in Table 2. The SPI has been calculated on an annual basis.

Table 2 Classification of drought on the SPI scale

\begin{tabular}{cc}
\hline Description & SPI magnitude \\
\hline Extremely dry & $\leq-2$ \\
Severely dry & -1.9 to -1.5 \\
Moderately dry & -1.4 to -1.0 \\
Near Normal & -0.9 to 0.9 \\
\hline
\end{tabular}

Drought is a duration phenomenon in that it refers to a time span, therefore, understanding the evolution of CDD is critical to better inferring the variability of drought. The occurrence of CDD and its relationship to seasonal drought was therefore explored using the Taylor diagram (Taylor, 2001). This method is a convenient way of summarizing the statistical association between two or more variables, and has been used in many climate studies (e.g., Fotso-Nguemo et al., 2018; Ongoma et al., 2018). The parameters involved are correlation, standard deviation and root mean square error.

Composite analysis was employed to investigate atmospheric patterns influencing precipitation during drought years. Composite analysis is a useful technique that involves the collection and averaging of meteorological variables of interest. These composites are then used to interpret patterns associated with given scenarios (Okoola, 1999; Ogwang et al., 2012). Here, composites of wind flow at $850 \mathrm{hPa}$, pressure vertical velocity (omega) and $\mathrm{RH}$ were constructed. The years considered were extreme (1992 and 2015) and severe (1995) drought years. These were compared with composites of the most recent wet year, 2007. The aim of this was to investigate circulation anomalies associated with drought years in contrast to those associated with wet years.

Following Singh and Rathor (1974), pressure was used in this study in place of altitude to investigate vertical motion. Mathematically, vertical velocity is given in pressure coordinates as:

$$
\omega=\frac{D p}{D t},
$$

where $\omega$ represents the Lagrangian rate of change in pressure with time $(\mathrm{Pa} / \mathrm{s})$; and $D p$ and $D t$ represent the time rate of change of pressure $(\mathrm{Pa} / \mathrm{s})$. Other studies (e.g., Libanda et al., 2016) refer the omega equation, a partial differential equation for vertical velocity given by:

$$
\sigma \nabla_{H}^{2} \omega+f^{2} \frac{\partial^{2} \omega}{\partial p^{2}}=f \frac{\partial}{\partial p}\left[v_{g} \times \nabla_{H}\left(\zeta_{g}+f\right)\right]-\nabla_{H}^{2}\left(v_{g} \times \nabla_{H} \frac{\partial \phi}{\partial p}\right),
$$


The following definitions are used in Equation 3 (see Holton, 1992). The static stability is given by $\sigma\left(\mathrm{rad} / \mathrm{s}\right.$, which is usually abbreviated as $\left.\mathrm{s}^{-1}\right) ; \nabla_{H}$ is the horizontal del operator; $\nabla_{H}^{2}$ is the horizontal Laplacian operator; $f$ is the Coriolis parameter, with the unit of $\mathrm{rad} / \mathrm{s}$ (approximately $10^{-4} / \mathrm{s}$, varying with latitude); $v_{g}$ is the geostrophic velocity vector $(\mathrm{m} / \mathrm{s}) ; \zeta_{g}$ is the geostrophic relative vorticity and is generally a scalar rotation thus dimensionless; $\phi$ is the geopotential $(\mathrm{m})$; and $p$ is defined as pressure $(\mathrm{Pa})$.

The main tools used for data analysis and presentation of results in this study are the $\mathrm{R}$ programming language, Climate Data Operators (CDO) and Grids Analysis and Display System (GrADS). The MDM (Meteorological Drought Monitoring) software was used to calculate SPI. A detailed description of this software is available in the work of Salehnia et al. (2017).

\section{Results}

\subsection{Seasonal cycle of precipitation}

In this study, the core of the rainy season was observed (Fig. 1) to occur during the December-February (DJF) months with over $60 \%$ of cumulative precipitation received during these months. This observation was also made by Hachigonta and Reason (2006) who studied the inter-annual variability of dry and wet events over Zambia.

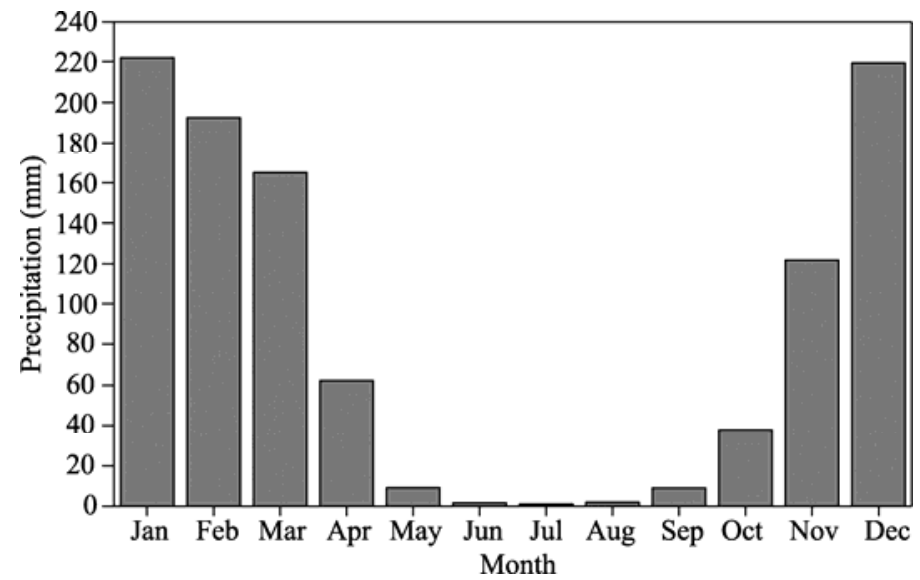

Fig. 1 Mean cycle of precipitation over Zambia for the period 1960-2016 based on GPCC (Global Precipitation Climatology Centre) data. The values were averaged over longitudes $21^{\circ} 30^{\prime} \mathrm{E}-34^{\circ} 00^{\prime} \mathrm{E}$ and latitudes $18^{\circ} 00^{\prime} \mathrm{S}-08^{\circ} 00^{\prime} \mathrm{S}$.

\subsection{Standardized precipitation index (SPI)}

Using the methods discussed in Section 2.2 of this paper, SPI results shown in Figure 2 indicate that Zambia experienced more dry years (28) than wet years (27) during the period 1960-2016. The most recent extremely dry event occurred in 2015. With reference to Table 2, the SPI categorized extremely dry (with a SPI value $\leq-2.0$ ) years over Zambia as 1992 and 2015, one severely dry $(-1.9$ to -1.5$)$ year as 1995 , moderately dry $(-1.4$ to -1.0$)$ years as $1972,1980,1987$, 1999 and 2005 , and 26 near normal years $(-0.9$ to 0.9$)$.

The monthly cycles of precipitation for extremely dry (1992 and 2015) and severely dry (1995) years were investigated to ascertain how they differ from a wet year (2007). The results are presented in Figure 3, which indicate that while precipitation started in October during both the extremely and/or severely dry years and the wet year, the overall magnitude was different, with less than $200 \mathrm{~mm}$ being received during the dry years and over $300 \mathrm{~mm}$ during the wet year, by the end of December. Similarly, the end of the rainy season was in late April or early May for both the dry years and wet year. However, the wet year was associated with more intense precipitation than the dry years. 


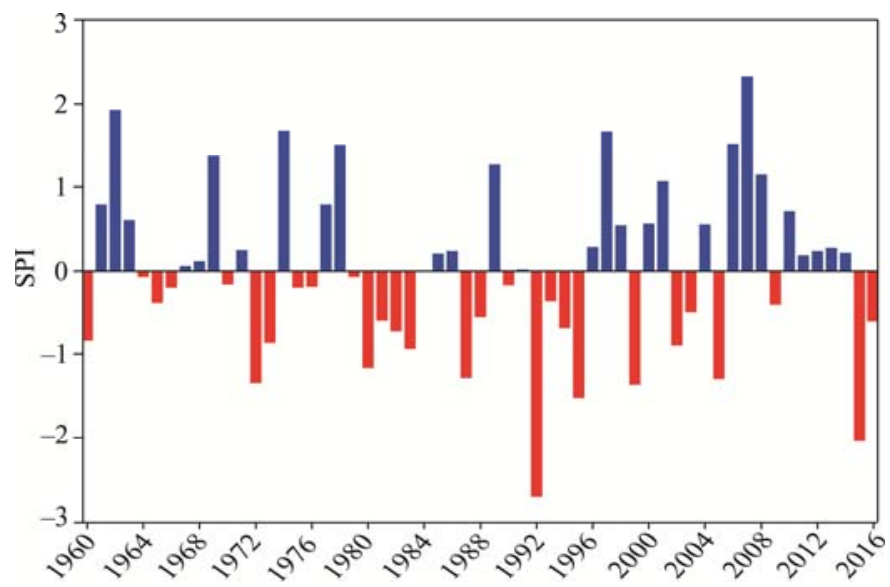

Fig. 2 Standardized precipitation index (SPI) results over Zambia for the period 1960-2016 based on GPCC data. The values were averaged over longitudes $21^{\circ} 30^{\prime} \mathrm{E}-34^{\circ} 00^{\prime} \mathrm{E}$ and latitudes $18^{\circ} 00^{\prime} \mathrm{S}-08^{\circ} 00^{\prime} \mathrm{S}$.

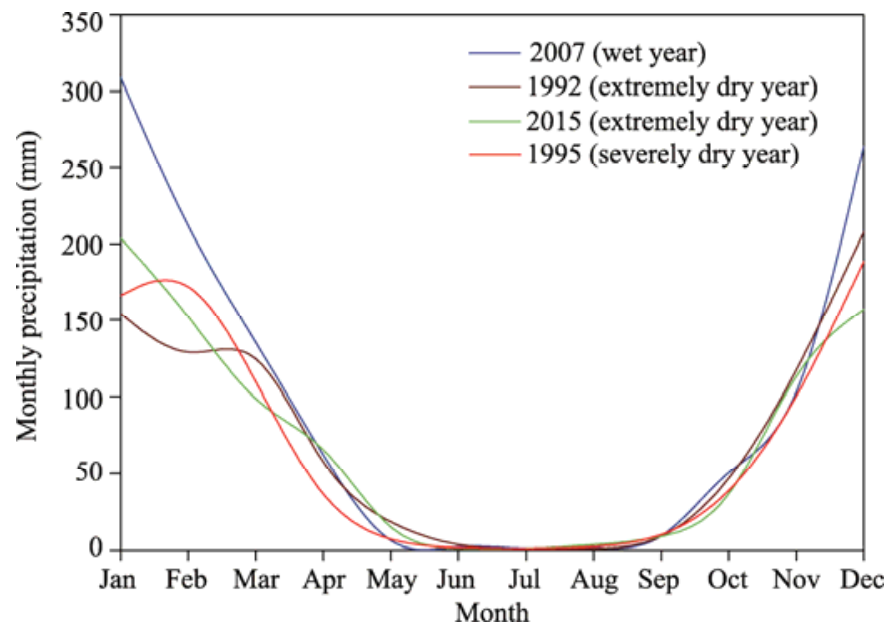

Fig. 3 Monthly cycles of precipitation for extremely dry years (1992 and 2015), severely dry year (1995) and wet year (2007)

The observed extremely (1992 and 2015) and severely (1995) dry years were investigated in terms of their spatial distribution of precipitation during the core of the rainy season (i.e., DJF). We subtracted drought years from the long term mean (LTM) to clearly capture the departure of precipitation from the LTM (Fig. 4). Results indicate a wetter northern half of Zambia and a drier southern half. Generally, the DJF LTM precipitation ranged from 800 to $850 \mathrm{~mm}$ over much of northern Zambia and was less than $800 \mathrm{~mm}$ over the Livingstone region in southern province. During the severely dry year 1995, negative departure from the LTM was experienced over much of the country within the range of 0-350 mm. However, positive anomalies of approximately 100 $\mathrm{mm}$ were observed around Mbala and the Lake Mweru Wantipa region (Fig. 4b). Figures $4 \mathrm{c}$ and $\mathrm{d}$ show the spatial variability during the extremely dry years of 1992 and 2015. The negative anomalies varied between 0 and $500 \mathrm{~mm}$ over much of Zambia. It is interesting to note however, that, similarly to DJF in 1995, positive anomalies of approximately $100 \mathrm{~mm}$ were observed in Lake Mweru and Lake Mweru Wantipa region of northern Zambia during the DJF in 2015.

\subsection{Evolution of consecutive dry days (CDD)}

In this study, the occurrence of CDD was investigated in terms of their statistical association with SPI (Fig. 5). To ease the computation, we removed the influences of dispersion by standardizing both CDD and SPI. Results shown in Figure 5 indicate a correlation coefficient of 0.6. The 


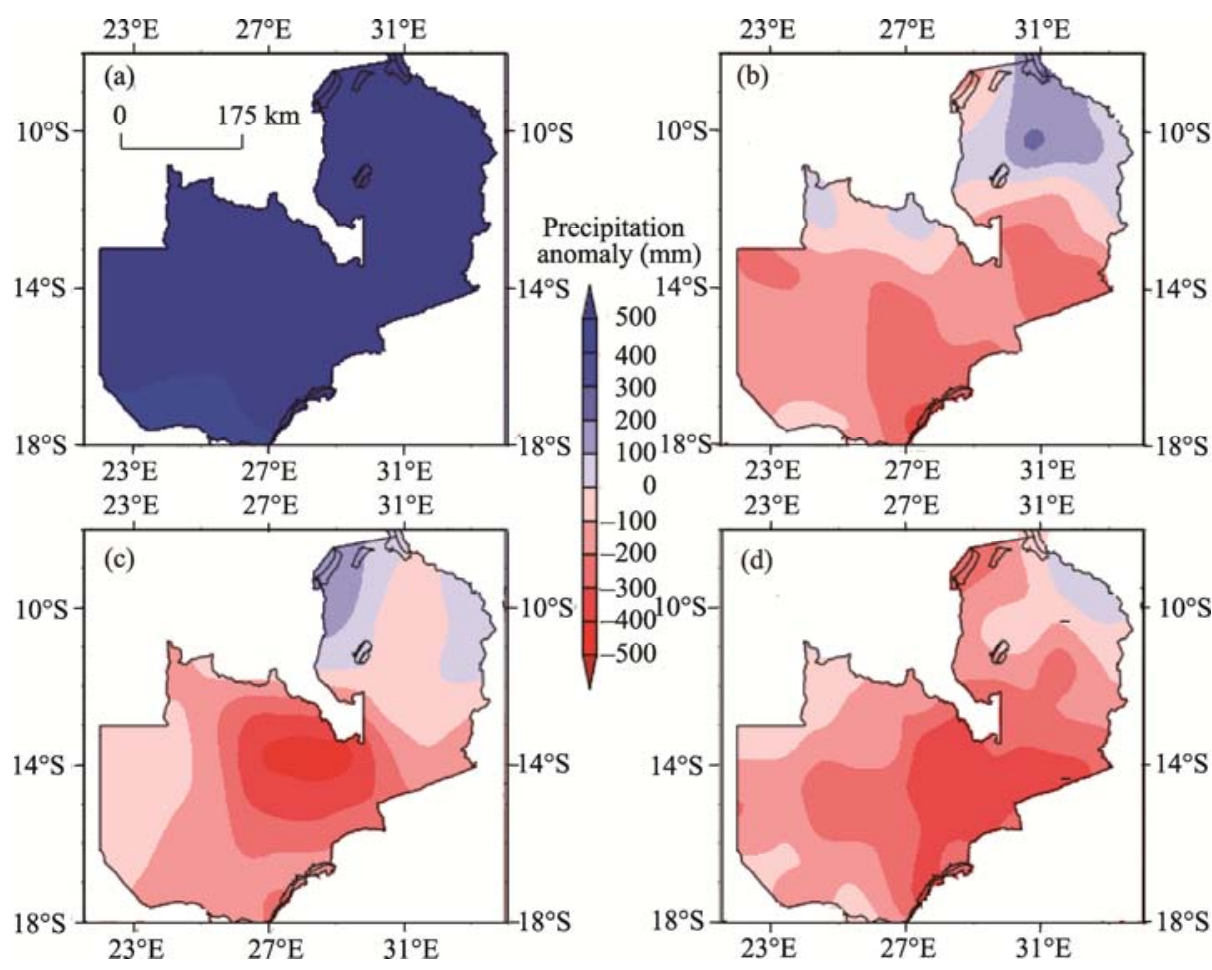

Fig. 4 DJF (December-February, the core of the rainy season) precipitation anomalies over Zambia, based on GPCC data. (a), long term mean (the period 1960-2016); (b), severely dry year 1995; (c), extremely dry year 2015; and (d), extremely dry year 1992.

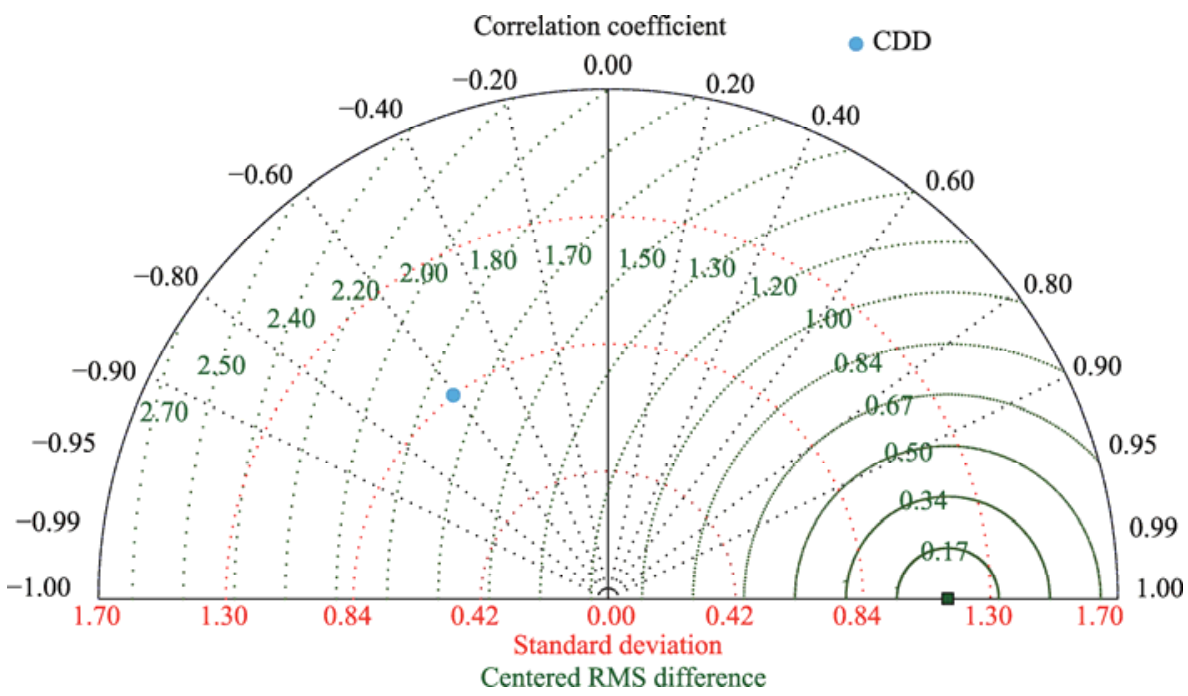

Fig. 5 Taylor diagram of consecutive dry days (CDD) versus SPI for the period 1983-2016 based on Africa Climatology Version 2 daily rainfall data. The values were averaged over longitudes $21^{\circ} 30^{\prime} \mathrm{E}-34^{\circ} 00^{\prime} \mathrm{E}$ and latitudes $18^{\circ} 00^{\prime} \mathrm{S}-08^{\circ} 00^{\prime} \mathrm{S}$. RMS, root-mean-square. The Taylor diagram has three axes: correlation coefficient (azimuthal position; black dotted line), standard deviation (radical distance from the origin; red dotted line) and centered RMS difference (distance from the reference point (green square); green dotted line).

centered root-mean-square (RMS) difference between CDD and SPI was given relative to the distance of the green square on the $x$-axis. The green contours show the RMS values. In this case, the RSM is 1.76. The standard deviation of CDD is proportional to the radial distance from the origin and is here equal to 0.84 . These results are in line with theoretical climatology, i.e., the more CDD are experienced in a season, the higher are the chances of experiencing drought (Duan 
et al., 2016).

A time series of CDD and SPI is shown in Figure 6. In line with the results from the Taylor diagram analysis, these results show that the occurrence of CDD was negatively correlated with SPI. Although the difference between CDD and SPI is minimal in some years (e.g., 1988), it is notable that there is a larger difference during extremely dry (i.e., 1992 and 2015) and severely dry (1995) years.

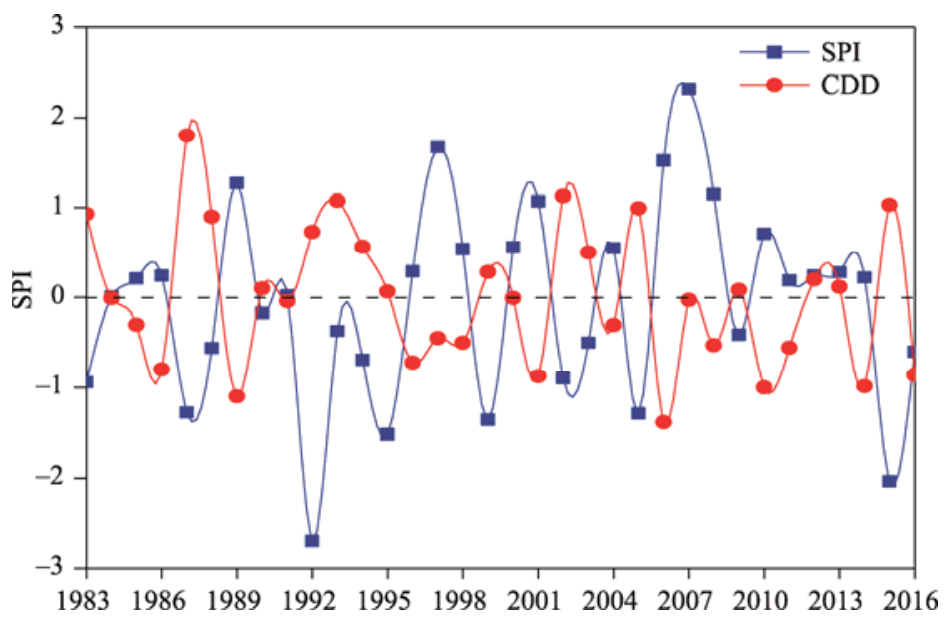

Fig. 6 Temporal variability of CDD and SPI for the period 1983-2016 based on Africa Climatology Version 2 daily rainfall data. The values were averaged over longitudes $21^{\circ} 30^{\prime} \mathrm{E}-34^{\circ} 00^{\prime} \mathrm{E}$ and latitudes $18^{\circ} 00^{\prime} \mathrm{S}-08^{\circ} 00^{\prime} \mathrm{S}$.

\subsection{Circulation patterns}

Anomalies in horizontal wind vectors at low-pressure levels are a key 'triggering' mechanism for precipitation. Convergence triggers the ascent of air and consequently, condensing of air. In contrast, divergence favors subsidence of air and consequently, drying of air (Ogwang et al., 2012). In this study, the horizontal wind vectors at $850 \mathrm{hPa}$ during the core of the rainy season (i.e., DJF) were investigated to ascertain the patterns of flow during years of extreme and (1992 and 2015) and severe (1995) drought. These were then contrasted with the patterns of flow in 2007, a generally wet year over Zambia. Results suggest that, during wet year, Zambia is influenced by a clockwise circulating low-pressure zone over south-eastern Angola, a second such zone over northern and eastern provinces, and a third over the Indian Ocean. These low-pressure zones are indicated with a red-colored 'L' in Figure 7a. In stark contrast, years of dryness (Figs. 7b and c) are characterized by an anti-clockwise circulating high-pressure zone over the south-western parts of Zambia. These high-pressure zones are marked with a red-colored ' $\mathrm{H}$ ' on Figures $7 b$ and c. Figure 7c was generated by averaging the DJF values for 1992 and 2015.
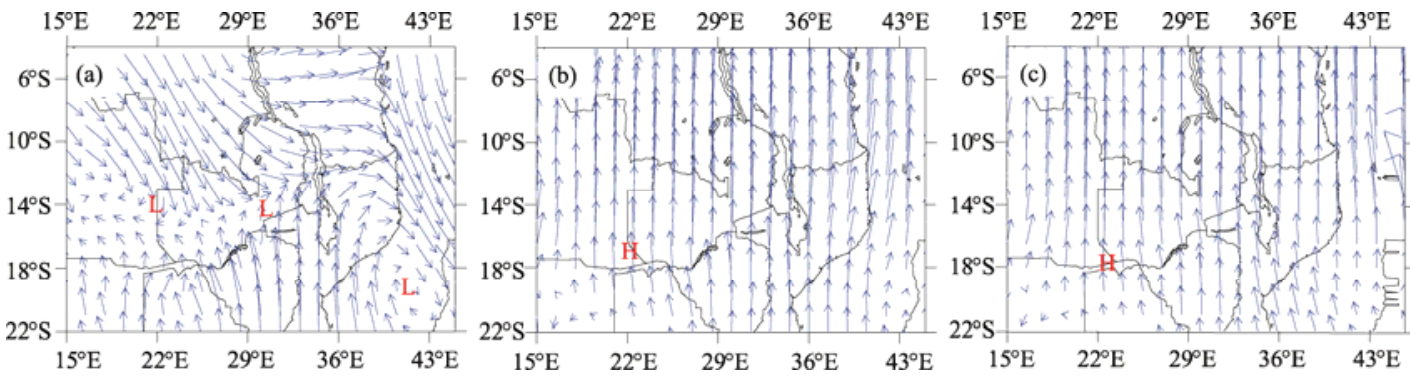

Fig. 7 Horizontal wind vectors at $850 \mathrm{hPa}$ during the core of the rainy season (i.e., DJF) for the wet year 2007 (a), the severely dry year 1998 (b), and the extremely dry years 1992 and 2015 (c), based on ERA-interim reanalysis data. The letters ' $\mathrm{L}$ ' indicates the low-pressure zone while ' $\mathrm{H}$ ' indicates the high-pressure zone.

Mean meridional cross section of DJF pressure vertical velocity (omega; Fig. 8) was also 
investigated with the aim of understanding the pressure vertical velocity associated with extremely dry years (1992 and 2015) and severely dry year (1992). Again, they were contrasted with the wet year 2007. Results show that 2007 (Fig. 8a) was characterized by negative anomalies which indicate rising motion especially over parts of north-western and Copperbelt provinces, i.e., longitudes $21^{\circ} 30^{\prime} \mathrm{E}-28^{\circ} 00^{\prime} \mathrm{E}$. In contrast, dry years (Figs. $8 \mathrm{~b}$ and c) were dominated by positive anomalies, which indicate sinking motion and suppression of precipitation.
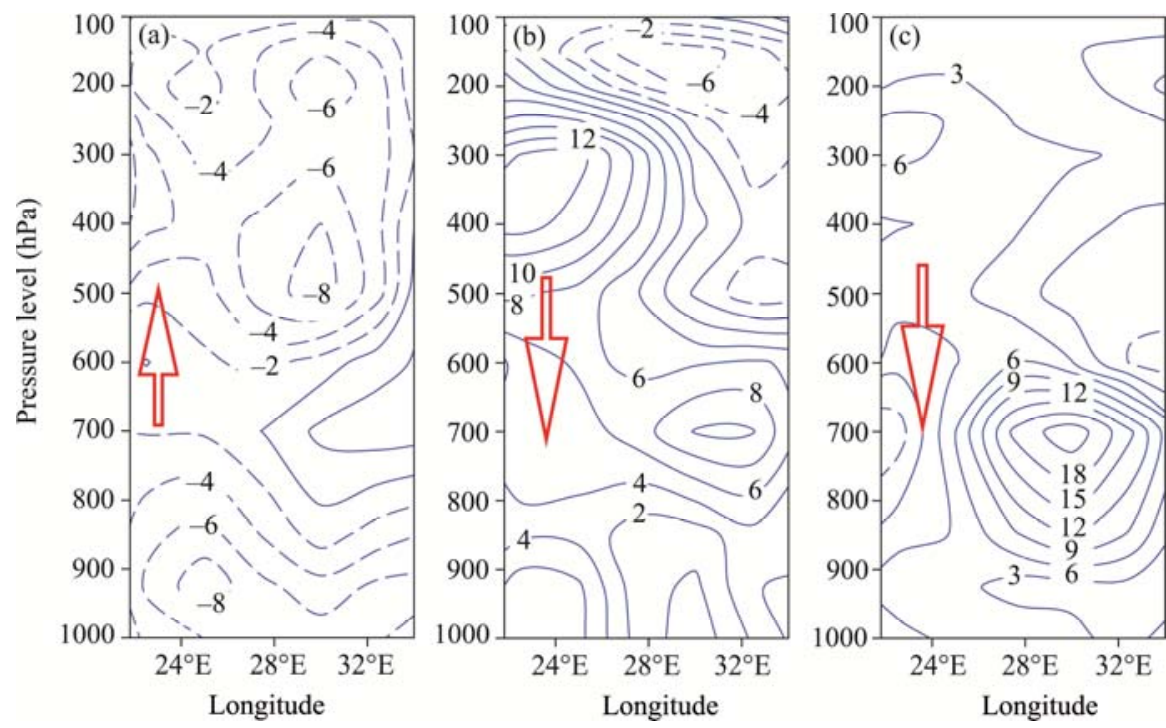

Fig. 8 Mean meridional cross section of DJF pressure vertical velocity (omega) anomaly $\left(\times 10^{-3} \mathrm{~Pa} / \mathrm{s}\right)$ for the wet year 2007 (a), the severely dry year 1995 (b), and the extremely dry years 1992 and 2015 (c), based on ERA-interim reanalysis data. The red upward arrow in (a) indicates rising motion while the downward arrows in (b) and (c) indicate sinking motion.

To further understand circulation patterns associated with drought years, we studied the amount of water vapor in the atmosphere (Fig. 9). This is usually expressed as a percentage (\%) as RH (Grinn-Gofroń and Bosiackaet, 2015). Previous studies have found strong statistical links between the occurrence of rainfall and high $\mathrm{RH}$ over a region. For instance, in a study of the 2010-2011 drought over Kenya, Ongoma et al. (2015) found positive anomalies of RH over the western part of the study area being positively correlated with above normal rainfall. Similarly, in this study, the spatial patterns of RH were explored. Results indicate that the wet year 2007 was associated with high RH values especially over north-western and Luapula provinces (Fig. 9a). Notably, the RH exhibited a reduction from the north to the south of the country and was positively correlated with rainfall patterns (Fig. 4a). During severely dry year (1995), most parts of the country experienced a reduction in RH with only north-western, Copperbelt and Luapula provinces experiencing an average of $60 \%$. The RH was less than $60 \%$ in the rest of the country. During extremely dry years (1992 and 2015), the whole country experienced a maximum average RH of only $50 \%$.

\section{Discussion}

In this study, we found that while the observed occurrences of drought (Fig. 2) seem sporadic, Zambia experienced a 5-year period of drought from 1990 to 1995, including the extremely dry year of 1992 that led to critical food shortages coupled with myriad societal problems (Tiffen and Mulele, 1994). It is notable that more precipitation was observed over Luapula, northern and north-western provinces of Zambia, with southern and parts of western provinces receiving the lowest amounts $(\leq 200 \mathrm{~mm})$. This observation was also made by Libanda et al. (2015) and by Hachigonta and Reason (2006) who described it as 'a downward gradient of precipitation from the north to the south of the country'. This downward gradient can be attributed to the influence of a 


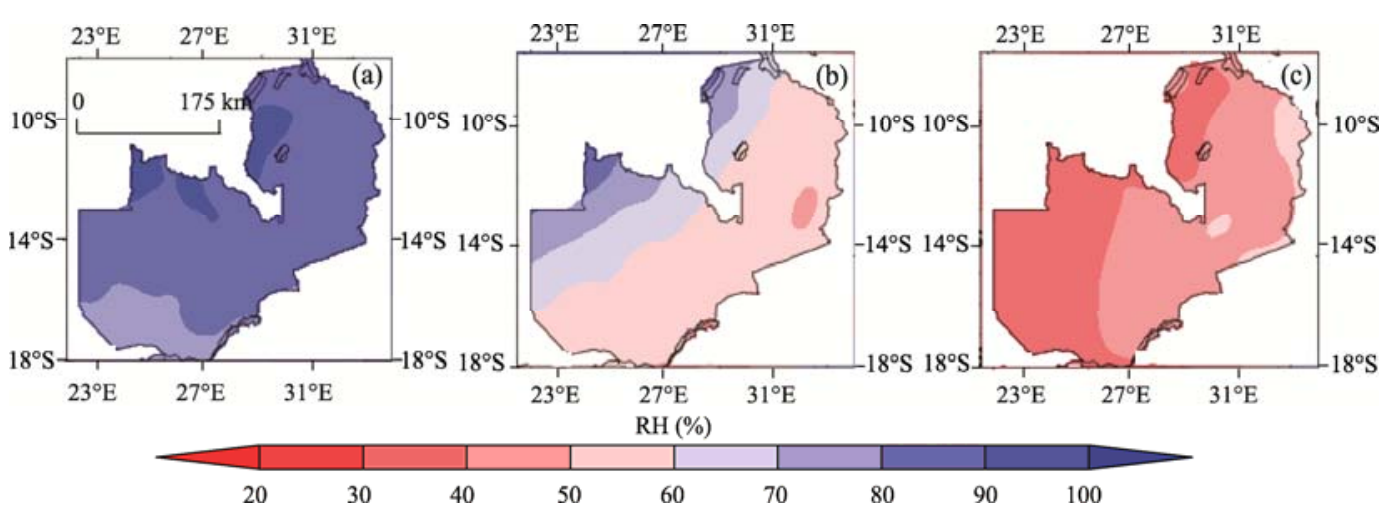

Fig. 9 Mean DJF relative humidity (RH) for the wet year 2007 (a), the severely dry year 1995 (b) and the extremely dry years 1992 and 2015 (c)

persistent low-pressure zone over eastern Angola (Fig. 7a), which distributes moisture to the northern half of Zambia. It is important to note that Lake Kariba, Zambia's main source of hydroelectricity, is located south of Lusaka, a region exhibiting stronger drought patterns. Zambia sources more than $95 \%$ of its electrical -energy needs from hydroelectricity. In recent years, whenever the country has experienced drought, Lake Kariba has had dangerously low water levels, leading to critical reductions in power generation and, as a consequence, adversely affecting all socio-economic activities in both Zambia and neighboring Zimbabwe (Hill, 2016). These results can therefore inform decision-making processes in water resource management.

The extremely dry (1992 and 2015) and severely dry (1995) years were investigated on the basis of their departure from the mean (Fig. 4a). Results shown in Figures. $4 \mathrm{~b}$ and $\mathrm{c}$ indicate that the northern half of the country, which receives more rainfall, suffers more precipitation deficits than the southern half. However, Tiffen and Mulele (1994) argue that the impacts of drought are felt more in the southern half of the country because of the dominant low precipitation patterns. Figure $4 \mathrm{~b}$ shows that Copperbelt and parts of north-western provinces had the highest precipitation deficit during the severely dry year of 1995. During the extremely dry year of 2015, the highest deficit was again over Copperbelt and north-western provinces, but it extended further to parts of Lusaka and Kariba. In 1992 (extremely dry year), the largest anomalies were observed in northern and Luapula provinces over Mpika, Kasama and Mansa.

It is interesting to note that in both dry and wet years, the rainy season generally started in October (Fig. 3) and ended in April or May. These findings indicate that the start and end of the rainy season may not necessarily be indicators of whether the year will experience drought; forecasting may need to focus on the intra-seasonal variability of rainfall. While the start and cessation of the rainy season are fundamental to determining planting dates for the agricultural sector, understanding intra-seasonal variability is also fundamental to preparing for probable dry spells during the year. The observed consecutive dry days have a huge negative impact on the agricultural sector because their occurrence reduces soil moisture (Hottenstein et al., 2015). Therefore, studying the variability of consecutive dry days closely will be key for strategic planning to ensure food security.

\section{Conclusions}

This study examined the spatio-temporal variability of drought over Zambia. The standardized precipitation index (SPI) was used to explore drought occurrence during the period 1960-2016. SPI successfully classified extremely dry (SPI value of $\leq-2.0$ ) years as 1992 and 2015, a severely dry $(-1.9$ to -1.5$)$ year as 1995 , moderately dry $(-1.4$ to -1.0$)$ years as $1972,1980,1987,1999$ and 2005 , and 26 near normal years $(-0.9$ to 0.9$)$. The occurrence of consecutive dry days was explored and it was found to be strongly negatively correlated with SPI with a correlation coefficient of -0.6 . 
Horizontal wind vectors at $850 \mathrm{hPa}$ were investigated during the core of the rainy season (December-February, DJF) to ascertain the patterns of flow during years of extreme and severe drought. These were contrasted with the patterns of flow in 2007, a generally wet year over Zambia. During wet years, Zambia is influenced by large-scale low-pressure zones which boost precipitation but tend to be indiscernible during years of dryness. Similar patterns (enhancement during wet years and reduction during drought years) were observed for omega (pressure vertical velocity) and relative humidity. If followed, these patterns may enable forecasting drought over Zambia and aid in strategic planning and management to limit the potential damage caused by drought.

\section{Acknowledgements}

The authors would like to express their gratitude to the National Centers for Environmental Prediction/National Center for Atmospheric Research (NCEP/NCAR) and the Joint Institute for the Study of the Atmosphere and Oceans (JISAO) for the data used in this study. The first author carried out this work while on a PhD scholarship sponsored by the University of Edinburgh; the university is hereby acknowledged. The useful and pertinent comments received from the anonymous reviewers and editors are much appreciated.

\section{References}

Bordi I, Fraedrich K, Petitta M, et al. 2005. Large-scale analysis of drought in Europe using NCEP/NCAR and ERA-40 re-analysis data sets. European Water, 9(10): 35-42.

Burke E J. 2011. Understanding the sensitivity of different drought metrics to the drivers of drought under increased atmospheric $\mathrm{CO}_{2}$. Journal of Hydrometeorology, 12(6): 1378-1394.

Dai A. 2011. Drought under global warming: a review. Wiley Interdisciplinary Reviews: Climate Change, 2(1): 45-65.

Dee D P, Uppala S M, Simmons A J, et al. 2011. The ERA-interim reanalysis: configuration and performance of the data assimilation system. Quarterly Journal of the Royal Meteorological Society, 137(656): 553-597.

Dogan S, Berktay A, Singh V. 2012. Comparison of multi-monthly rainfall-based drought severity indices, with application to semi-arid Konya closed basin, Turkey. Journal of Hydrology, 470-471: 255-268.

Duan Y, Ma Z, Yang Q. 2016. Characteristics of consecutive dry days variations in China. Theoretical and Applied Climatology, 130(1-2): 701-709.

Field C B, Barros V, Stocker T F, et al. 2012. IPCC-Intergovernmental Panel on Climate Change. Managing the risks of extreme events and disasters to advance climate change adaptation. A special report of working groups I and II of the intergovernmental panel on climate change. Cambridge: Cambridge University Press, 65-108.

Fotso-Nguemo T, Chamani R, Yepdo Z D, et al. 2018. Projected trends of extreme rainfall events from CMIP5 models over Central Africa. Atmospheric Science Letters, 19(2): e803.

Frich P, Alexander L V, Della-Marta P, et al. 2002. Observed coherent changes in climatic extremes during the second half of the twentieth century. Climate Research, 19(3): 193-212.

Grinn-Gofron A, Bosiacka B. 2015. Effects of meteorological factors on the composition of selected fungal spores in the air. Aerobiologia, 31(1): 63-72.

Hachigonta S, Reason C J C. 2006. Interannual variability in dry and wet spell characteristics over Zambia. Climate Research, 32: 49-62.

Hayes M J, Svoboda M D, Wall N, et al. 2011. The Lincoln declaration on drought indices: universal meteorological drought index recommended. Bulletin of the American Meteorological Society, 92(4): 485-488.

Hill M. 2016. World's Biggest Dam Has 'Extremely Dangerous' Low Water Levels. [2017-11-24]. https://www.bloomberg.com/news/articles/2016-01-08/world-s-biggest-dam-has-extremely-dangerous-low-water-levels.

Holton J R. 1992. An Introduction to Dynamic Meteorology. San Diego: Academic Press, 166-175.

Hottenstein J, Ponce-Campos G, Moguel-Yanes J, et al. 2015. Impact of varying storm intensity and consecutive dry days on grassland soil moisture. Journal of Hydrometeorology, 16(1): 106-117.

Karl T R, Nicholls N, Ghazi A. 1999. CLIVAR/GCOS/WMO workshop on indices and indicators for climate extremes workshop summary. Climate Change, 42(1): 3-7.

Libanda B, Barbara N, Bathsheba M. 2015. Rainfall variability over northern Zambia. Journal of Scientific Research and Reports, 6(6): 416-425.

Libanda B, Ogwang B, Ongoma V, et al. 2016. Diagnosis of the 2010 DJF flood over Zambia. Natural Hazards, 81(1): 189-201.

Libanda B, Zheng M, Banda N. 2017a. Variability of extreme rainfall over Malawi. Geographical Pannonica, 4(21): 212-223. 
Libanda B, Allan D, Noel B, et al. 2017b. Predictor selection associated with statistical downscaling of precipitation over Zambia. Asian Journal of Physical and Chemical Sciences, 1(2): 1-9.

Libanda B, Ngonga C. 2018. Projection of frequency and intensity of extreme precipitation in Zambia: a CMIP5 study. Climate Research, 76(1): 59-72.

Loomis R S. 1999. Feeding a world population of more than eight billion people: A challenge to science. Crop Science, 39(4): 1250.

McKee T B, Doesken N J, Kleist J. 1993. The relationship of drought frequency and duration to time scales. In: Proceedings of the $8^{\text {th }}$ Conference on Applied Climatology. Anaheim: American Meteorological Society, 179-184.

Monacelli G. 2005. Drought assessment and forecasting. Geneva: World Meteorological Organization (WMO). http://www.wmo.int/pages/prog/hwrp/documents/regions/DOC8.pdf

Muchuru S, Landman W, DeWitt D, et al. 2014. Seasonal rainfall predictability over the Lake Kariba catchment area. Water SA, 40(3): 461, doi: http://dx.doi.org/10.4314/wsa.v40i3.9.

New Yorker. 2016. One of Africa's biggest dams is falling apart. [2017-10-11]. https://www.newyorker.com/tech/elements/one-of-africas-biggest-dams-is-falling-apart.

Ngarukiyimana J P, Fu Y, Yang Y, et al. 2017. Dominant atmospheric circulation patterns associated with abnormal rainfall events over Rwanda, East Africa. International Journal of Climatology, 38(1): 187-202.

Nicholson S E, Grist J P. 2003. The seasonal evolution of the atmospheric circulation over West Africa and equatorial Africa. Journal of Climate, 16(7): 1013-1030.

Novella N S, Thiaw W M. 2013. African Rainfall Climatology Version 2 for Famine Early Warning Systems. Journal of Applied Meteorology and Climatology, 52(3): 588-606.

Ogwang B A, Tan G, Haishan C. 2012. Diagnosis of September-November drought and the associated circulation anomalies over Uganda. Pakistan Journal of Meteorology, 9(17): 11-24.

Okoola R E. 1999. A diagnostic study of the Eastern Africa monsoon circulation during the northern hemisphere spring season. International Journal of Climatology, 19(2): 143-169.

Ongoma V, Guirong T, Ogwang B A, et al. 2015. Diagnosis of seasonal rainfall variability over East Africa: A case study of 2010-2011 drought over Kenya. Pakistan Journal of Meteorology, 11(22): 13-21.

Ongoma V, Chen H, Gao C, et al. 2017. Future changes in climate extremes over Equatorial East Africa based on CMIP5 multimodel ensemble. Natural Hazards, 90(2): 901-920.

Ongoma V, Chen H, Gao C. 2018. Evaluation of CMIP5 twentieth century rainfall simulation over the equatorial East Africa. Theoretical and Applied Climatology, doi: https://oi.org/10.1007/s00704-018-2392-x.

Salehnia N, Alizadeh A, Sanaeinejad H, et al. 2017. Estimation of meteorological drought indices based on AgMERRA precipitation data and station-observed precipitation data. Journal of Arid Land, 9(6): 797-809.

Santos J F, Pulido-Calvo I, Portela M M. 2010. Spatial and temporal variability of droughts in Portugal. Water Resources Research, 46, W03503, doi: 10.1029/2009WR008071.

Scheff J, Frierson D M W. 2012. Robust future precipitation declines in CMIP5 largely reflect the poleward expansion of model subtropical dry zones. Geophysical Research Letters, 39(18): L18704, https://doi.org/10.1029/2012GL052910.

Schneider U, Ziese M, Meyer-Christoffer A, et al. 2016. The new portfolio of global precipitation data products of the Global Precipitation Climatology Centre suitable to assess and quantify the global water cycle and resources. Proceedings of the International Association of Hydrological Sciences, 374: 29-34.

Singh U S, Rathor H S. 1974. Reduction of the complete omega equation to the simplest form. Pure and Applied Geophysics, 112(1): 219-223.

Taylor K E. 2001. Summarizing multiple aspects of model performance in a single diagram. Journal of Geophysical Research, 106(D7): 7183-7192.

Taylor K E, Stouffer R J, Meehl G A. 2012. An overview of CMIP5 and the experiment design. Bulletin of the American Meteorological Society, 93(4): 485-498.

Tiffen M, Mulele M R. 1994. The environmental impact of the 1991-92 drought on Zambia. A report for IUCN - The world conservation union. [2018-03-06]. https://portals.iucn.org/library/sites/library/files/documents/1994-017.pdf.

Trenberth K E, Fasullo J T. 2009. Global warming due to increasing absorbed solar radiation. Geophysical Research Letters, 36(7): L07706, https://doi.org/10.1029/2009GL037527.

Udmale P, Ichikawa Y S, Kiem A, et al. 2014. Drought Impacts and Adaptation Strategies for Agriculture and Rural Livelihood in the Maharashtra State of India. The Open Agriculture Journal, 8(1): 41-47.

Uhe P, Philip S, Kew S, et al. 2017. Attributing drivers of the 2016 Kenyan drought. International Journal of Climatology, 38(S1): e554-e568.

Zargar A, Sadiq R, Naser B, et al. 2011. A review of drought indices. Environmental Reviews, 19(1): 333-349.

Zhao T, Dai A. 2015. The magnitude and causes of global drought changes in the twenty-first century under a low-moderate emissions scenario. Journal of Climate, 28(11): 4490-4512. 